\title{
Ciencia y conciencia: el difícil avance por la senda del conocimiento, del bien común, cuando se debe lidiar con nuestros propios conflictos de interés
}

En esencia, todos nos sentimos mejor cuando en nuestro actuar se nos reconoce, se nos agradece, pero particularmente más cuando hacemos el bien, sin importar a quien y sin espera de retribución. Es por ello, que la dicha es tan grande cuando el reconocimiento y agradecimiento de los otros surgen espontáneamente y de manera inesperada. En tal dinámica de percepción individual se hace factible que como sociedad, donde todos debiésemos respetarnos, realmente logremos contribuir y encaminarnos correctamente hacia el anhelado bien común.

Hacer buena ciencia, esto es, generar conocimiento que propenda al bien común, implica ser conscientes de nuestras propias limitaciones sobre el entendimiento que tenemos de la verdad tras un fenómeno particular y de los intereses propios que nos motivan a su estudio. El buen médico, en esencia el buen samaritano, actúa esperando sólo ayudar, eventualmente curar o aliviar y regocijarse con el agradecimiento natural que perciba desde aquel que asiste. A su vez el buen científico, se regocija, en esencia, con el entender mejor, con el descubrimiento y con el dar solución correcta a un problema por pequeño que sea. Tanto el médico como el científico se alejan del bien común cuando los conflictos de interés nublan su actuar. Todo ginecólogo obstetra, como médico y científico, en pos del bien común de madre e hijo, debe necesariamente obrar con ciencia y conciencia, nunca abogarse la verdad absoluta y mantener siempre en mente sus propios conflictos de interés.

Hoy en día en medicina sobran las experiencias en donde por abogarnos la verdad y desconocer nuestros propios conflictos de interés minamos nuestra capacidad de contribuir al conocimiento, de obrar con vocación de servicio y de avanzar hacia el bien común. En lo mediático y en lo histórico, visiones religiosas, políticas, intereses económicos y deseos de reconocimiento 0 de retribución, todos mal entendidos, transformados en dogma o derechos mal atribuidos, nos han llevado a prejuzgar, actuar erróneamente y peor aún justificarnos frente a la inquisición para eludir nuestra responsabilidad y sus consecuencias.

Sin extenderse demasiado, aquí exploramos tres dimensiones que minan el acto médico con ciencia y conciencia. La panacea, el dogma y la estigmatización.

De la panacea, medicamento mítico que cura todas las enfermedades o prolonga indefinidamente la vida. Desde la edad media los alquimistas le buscaron incesantemente y muchos charlatanes comercializaron indebidamente entre incautos esperanzados en sanar. Con conocimiento o carente de él, la historia nos enseña que, frente al fracaso de las alternativas comunes o razonables, el ser humano busca o confía en opciones, aparentemente insensatas, que finalmente mitigan su dolor. Así también, muchos médicos han atribuido o descartado erróneamente un rol terapéutico a opciones que, contando con consenso de expertos o poder estadístico, se plantearon como alternativa. Por ejemplo, desde el siglo XV, en tiempos de Girolamo Fracastoro, hasta los inicios del siglo XX el estándar era el uso de mercurio para el tratamiento de la sífilis y hasta fines del siglo XX la vagotomía selectiva lo era para el tratamiento de la úlcera. Ambas condiciones, hoy sabidas de origen bacteriano y tratadas efectivamente con antibióticos. Sin embargo, el beneficio de los antibióticos en estas y otras condiciones ha promovido su sobreuso o indicación, por ejemplo, ante síntomas respiratorios inespecíficos o de origen viral, remedando la panacea y gatillando efectos adversos por resistencia o daño de la microbiota natural que en todo ser humano cohabita 
en intestino y de alguna forma regula expresión génica e inmunidad (1). En la farmacopea actual, pocas son las innovaciones recientes que muestren el beneficio e impacto que los antibióticos han tenido en curar la enfermedad infecciosa. En oncología, la eficacia del Metotrexato en curar la enfermedad del trofoblasto persistente, alcanza tasas similares de éxito (2). Menos probable aún es que por tanto exista la panacea, aunque algunos medicamentos han mostrado beneficios más allá de su destino terapéutico original (ej. aspirina, estatinas, sildenafil) (3-5). Desde la perspectiva del conflicto de interés, las empresas farmacéuticas apoyan y promueven estudios que confirmen el rol terapéutico y beneficios adicionales ('off label use"), con menos efectos adversos, de nuevas formulaciones, que no necesariamente impactan significativamente en términos de sobrevida o calidad de vida. Eso se traduce en redundancia de publicaciones científicas favorables, simposios patrocinados, que reditúan en convencimiento médico colectivo de eficacia independiente de su real costo-efectividad o aplicabilidad en una población particular (6-10). Vincularse con las empresas, no es un mal, pero resta independencia al momento de elegir objetivamente o recomendar algo. En tal escenario reconocer nuestros vínculos hace manifiesto el conflicto de interés y a la vez permite ponderar al otro la objetividad de nuestras propias aseveraciones. Como médicos, debemos además ser conscientes de las limitaciones de nuestras acciones terapéuticas y de los efectos indeseados que ellas puedan tener cuando se aplican indebidamente o sin criterio, ello incluye el estrago psicológico, social y económico que pueda ocasionar en el o la paciente. El principio de primum non nocere debe ser sopesado ante todo acto médico o quirúrgico que se proponga, ya sea con fines preventivos, curativos o paliativos. A modo de ejemplo, ante la desesperación que genera un cáncer que progresa, el uso de drogas de alto costo, con beneficio objetivo limitado, justifica su recomendación, ¿o resulta más samaritano el ofrecer u optimizar la paliación? ¿o ante una paciente que tiene el miedo al parto se justifica promover la cesárea? ¿o ante un paciente que teme al dolor o sufrimiento de la enfermedad, el apoyar la eutanasia? Un conflicto de interés propio se evidencia cuando nos negamos a aceptar que individualmente no podemos curar, cuando si otros pueden ofrecer opciones más efectivas o paliar, o cuando preferimos alimentar nuestro orgullo de infalibilidad u osadía y peor aún decidimos ofrecer una terapia, preconcebidamente inefectiva, pero que nos reditúa económicamente. Ello tiene como consecuencia la desconfianza, el deterioro en la relación médico paciente y la judicialización del acto médico. Desde nuestra especialidad, debemos revisar y revisitar periódica y críticamente las indicaciones de cesárea, de inducciones electivas, uso injustificado de ultrasonografía, de suplementos vitamínicos, hormonoterapia, para evitar que se conviertan en una panacea indeseada que conlleve efectos adversos o no deseados.

El dogma, según el Diccionario de la Real Academia Española, es una proposición que se asume como un principio innegable o irrefutable de una ciencia o doctrina. En medicina, la aceptación general por la comunidad de especialistas y contar con evidencia científica que confirme la hipótesis, son los determinantes principales que consolidan el dogma. Todo aquello que no es medible, demostrable, inentendible y que particularmente contradice el dogma de los eruditos, determina rechazo o desprestigio. Talentos universales han debido lidiar con el repudio de pares cuando su teoría y evidencia contradicen el dogma. Tal es el caso del rechazo que generaron Paracelso y Vesalio al rebatir algunos de los dogmas fisiológicos de Galeno los cuales imperaron por más de 1000 años entre los médicos. Hasta no contar con el instrumento que mida y la disciplina que explore, el dogma se mantiene. Así lo plantearon Galileo, Copérnico, Newton y Einstein. El rigor científico permite rebatir el dogma, pero también justifica el escepticismo frente a lo que no se entiende o se desconoce. Publicar resultados que rebaten el dogma o que muestran resultados negativos con terapias consideradas de consenso, siempre es más difícil o eventualmente imposible. Entre los casos más recientes, la relación del Helycobacter Pilori con la etiopatogenia de la úlcera gástrica y del cáncer gástrico y el rechazo recibido en su momento por la comunidad científica al plantear sus hallazgos por parte de los actuales Premio Nobel Marshall y Warren (11). Dentro de los dogmas vigentes está el justificar las acciones terapéuticas basado en la evidencia, en lo cuantificable. Eso genera en gran parte el antagonismo entre medicina alopática u ortodoxa y las medicinas tradicionales, complementarias $\mathrm{y} / \mathrm{o}$ alternativas (definidas y abreviadas como MAC por la Organización Mundial de la Salud, OMS). Al carecer de evidencia científica y de instrumentos que cuantifiquen la magnitud del efecto, la propiedad terapéutica o la relación causal no existe. Tal fue el caso de los efectos terapéuticos de la acupuntura y que ahora no son cuestionados en su eficacia para el manejo del dolor y ahora existe entendimiento de los mecanismos explicatorios de su efecto (12). Como médicos no podemos aprobar que se hagan 
propuestas terapéuticas que afecten negativamente a nuestros pacientes, y más aún si carecen de validación. Sin embargo, tampoco podemos desconocer nuestra propia ignorancia, nuestras limitaciones y por ende abogarnos la verdad $y$ desprestigiar o desvirtuar algo que no conocemos o entendemos plenamente, un conflicto de interés vinculado al conocimiento. Tal es el caso de los trastornos cognitivos, su relación con otras enfermedades y de los efectos negativos o positivos que pueden tener ciertas terapias, propuestas por la medicina psicosomática, china, ayurbédica, u otras, en la historia natural de estas enfermedades u otras coexistentes o asociadas (13-17). A las nuevas generaciones de médicos debemos motivarlos a pensar, a rebatir con argumentos el dogma, a propender a la medicina integrativa y buscar nuevos instrumentos o diseños experimentales que nos permitan explicar lo que no entendemos a fin de encontrar mejores soluciones terapéuticas.

Finalmente, la estigmatización, según las Naciones Unidas, como un fenómeno sociocultural profundamente arraigado, es el origen de muchas violaciones a los derechos humanos y la causa de que grupos humanos enteros de población resulten desfavorecidos. El estigma se entiende como un proceso de deshumanización, descrédito y menosprecio de las personas pertenecientes a ciertos grupos, fundado a menudo en un sentimiento de disgusto. Así, el estigma se asocia a un atributo, calidad o identidad que se considera 'inferior' o 'anormal' y se basa en una brecha socialmente construida entre 'nosotros' y 'ellos' (18). Históricamente el sexo y su diversidad, la etnia, la religión, la pobreza, el analfabetismo, la discapacidad, la inmigración y las enfermedades de la cognición han sido objeto de discriminación y estigmatización. Desde la medicina, ello ha motivado restricciones o abusos al momento de participar en protocolos de investigación y tener acceso con equidad al diagnóstico y continuidad del tratamiento de las enfermedades que los afectan. En nuestra esfera, un ejemplo es el derecho a nacer o recibir tratamiento en casos de síndrome de Down o las repercusiones sociales que tiene el diagnóstico y tratamiento del VIH (19-21). Para nuestro país, los movimientos inmigratorios han generado sentimientos en los profesionales médicos que pueden conducir a la estigmatización de ciudadanos los cuales merecen el mismo trato y el mejor de nuestro conocimiento en relación a las particularidades que algunas enfermedades puedan tener en ellos. Nuestro enfoque específico debe ser similar al enfrentamiento que tenemos con respeto frente a la enfermedad de un niño, un adulto, una embarazada, o un anciano, independiente de la etnia, idioma o cultura de origen.

Para evitar la panacea, el dogma y la estigmatización, resulta relevante revisar periódicamente las experiencias clínicas y los resultados propios obtenidos con las terapias recomendadas, el contrastar y revisar críticamente la evidencia existente para el manejo de escenarios clínicos determinados y el actualizar las guías clínicas que soportan un actuar y decidir sin conflicto de interés. El análisis crítico debe además extenderse a variables o situaciones que pueden poner en jaque la pertinencia de un acto médico que tradicionalmente se consideró como permitido. Un ejemplo de ellos es el manejo integral y humanizado del parto, con respeto y seguridad.

En este número se incluyen trabajos que permiten ejemplificar y reflexionar sobre los aspectos antes mencionados.

\section{Dr. Mauricio Cuello Fredes}

Profesor Obstetricia y Ginecología

Editor jefe

Revista SOCHOG 
1) Bogdanos DP, Sakkas LI. From microbiome to infectome in autoimmunity. Curr Opin Rheumatol. 2017; doi:10.1097/BOR.0000000000000394.

2) Lawrie TA, Alazzam M, Tidy J, Hancock BW, Osborne R. First-line chemotherapy in low-risk gestational trophoblastic neoplasia. Cochrane Database Syst Rev. 2016; (6):CD007102

3) May MB, Glode A. Novel Uses for Lipid-Lowering Agents. J Adv Pract Oncol. 2016; 7(2):181-187

4) Serhan $\mathrm{CN}$. Treating inflammation and infection in the 21st century: new hints from decoding resolution mediators and mechanisms. FASEB J. 2017; 31(4):1273-1288

5) Itani N, Skeffington KL, Beck C, Giussani DA. Sildenafil therapy for fetal cardiovascular dysfunction during hypoxic development: studies in the chick embryo. J Physiol. 2017; 595(5):15631573

6) Paumgartten FJ. Pharmaceutical lobbying in Brazil: a missing topic in the public health research agenda. Rev Saude Publica. 2016; 50:70

7) Maekawa T. Ethics for clinical research. Rinsho Ketsueki. 2016;57(10):2301-2308

8) Mitchell AP, Basch EM, Dusetzina SB. Financial Relationships With Industry Among National Comprehensive Cancer Network Guideline Authors. JAMA Oncol. 2016; 2(12):1628-1631

9) Cosgrove L, Vannoy S, Mintzes B, Shaughnessy AF. Under the Influence: The Interplay among Industry, Publishing, and Drug Regulation. Account Res. 2016; 23(5):257-79

10) Marshall BJ. The 1995 Albert Lasker Medical Research Award. Helicobacter pylori. The etiologic agent for peptic ulcer. JAMA. 1995; 274(13):10646

11) Zhang F, Wu L, Zhao J, Lv T, Hu Z, Weng Z, Wang $\mathrm{S}$, Wu H, Liu H. Neurobiological Mechanism of Acupuncture for Relieving Visceral Pain of Gastrointestinal Origin. Gastroenterol Res Pract. 2017; 2017:5687496

12) Chauhan A, Semwal DK, Mishra SP, Semwal RB. Ayurvedic concept of Shatkriyakala: a traditional knowledge of cancer pathogenesis and therapy. $J$ Integr Med. 2017; 15(2):88-94
13) Prasher B, Gibson G, Mukerji M. Genomic insights into ayurvedic and western approaches to personalized medicine. J Genet. 2016; 95(1):20928

14) Khan I, Samson SE, Grover AK. Antioxidant Supplements and Gastrointestinal Diseases: A Critical Appraisal. Med Princ Pract. 2017; doi: 10.1159/000468988

15) Yu WH, Zhang N, Qi JF, Sun C, Wang YH, Lin M. Arsenic and Mercury Containing Traditional Chinese Medicine (Realgar and Cinnabar) Strongly Inhibit Organic Anion Transporters, Oat1 and Oat3, In Vivo in Mice. Biomed Res Int. 2015; 2015:863971

16) Yoon JS, Hwang DW, Kim ES, Kim JS, Kim S, Chung HJ, Lee SK, Yi JH, Uhm J, Won YW, Park $\mathrm{BB}$, Choi JH, Lee YY. Anti-tumoral effect of arsenic compound, sodium metaarsenite (KML001), in non-Hodgkin's lymphoma: an in vitro and in vivo study. Invest New Drugs. 2016; 34(1):1-14

17) Shin SS, Song JH, Hwang B, Noh DH, Park SL, Kim WT, Park SS, Kim WJ, Moon SK. HSPA6 augments garlic extract-induced inhibition of proliferation, migration, and invasion of bladder cancer EJ cells; Implication for cell cycle dysregulation, signaling pathway alteration, and transcription factor-associated MMP-9 regulation. PLoS One. 2017; 12(2): e0171860

18) Naciones Unidas: Report of the Special Rapporteur on the human right to safe drinking water and sanitation, Catarina de Albuquerque Stigma and the realization of the human rights to water and sanitation. 2012

19) McDowell M, O'Keeffe M. Public services for children with special needs: discrimination by diagnosis?. J Paediatr Child Health. 2012; 48(1):25

20) McCabe LL, McCabe ER. Down syndrome: coercion and eugenics. Genet Med. 2011; 13(8):708-10

21) Frye $V$, Paige $M Q$, Gordon $S$, Matthews $D$, Musgrave G, Kornegay M, Greene E, Phelan JC, Koblin BA, Taylor-Akutagawa V. Developing a community-level anti-HIV/AIDS stigma and homophobia intervention in new York city: The project CHHANGE model. Eval Program Plann. 2017; 63: 45-53 